\title{
Novel drugs and drug combinations for treating tuberculosis
}

The original version of this Therapeutics article (BMJ 2014;349:g5948, doi:10.1136/bmj.g5948) advised that "Hypoalbuminaemia was a risk factor for QT interval prolongation, and delamanid should not be used if the serum albumin concentration is above $2.8 \mathrm{~g} / \mathrm{dL}$." The recommendation for delamanid's use was incorrect and should have read, "Hypoalbuminaemia was a risk factor for QT interval prolongation, and delamanid should not be used if the serum albumin concentration is below $2.8 \mathrm{~g} / \mathrm{dL}$." This error has now been corrected in the online version of the article.

Cite this as: BMJ 2014;349:96563

๑ BMJ Publishing Group Ltd 2014 